\section{Review needed of risks}

SIR - The recent report by Gardner et al. ${ }^{1}$ on the association of childhood leukaemia and employment at the British Nuclear fuels plant at Sellafield calls for an urgent examination of the current and proposed radiation protection standards. Such a review requires the data on relative risks to be converted to absolute risks so that their real significance, and the observed excess risk to be associated with a parental dose, can be assessed.

The baseline fatality risk due to leukaemia in the age range up to 25 in England and Wales can be calculated from the Office of Population Censuses and Surveys' age-specific mortality rates ${ }^{2}$. In 1986, it was about 375 per million. The relative risk factors reported by Gardner et $a l .^{1}$ can be reduced by 1 to give the excess relative risk factor which can then be applied to this baseline, given that the relative risk factor is the same for fatal and non-fatal causes.

The association with dose may be either with the dose in the few months before conception or with the total dose before conception. For the former case, Gardner's results suggest an excess risk factor of about 6.7 for a dose in excess of 10 millisieverts (a mean dose of perhaps 20 $\mathrm{mSv}$ ) in the relevant 6 months. The excess fatality risk is then $6.7 \times 375 \times 10^{-6}$ or 2.5 $\times 10^{-8}$ per birth. This risk, an order of magnitude less than the risk per birth of serious congenital abnormalities, is small, but not negligible. For the second case, the excess relative risk factor seems to be about 6.3 for total doses greater than 100 $\mathrm{mSv}$ (a mean dose of perhaps $200 \mathrm{mSv}$ ), which is not significantly different. For an average paternal age of about 30 at the time of conception, the gonad dose from natural sources would be about $30 \mathrm{mSv}$. If accumulated dose is the relevant factor, it seems that paternal exposure to natural sources could well be the predominant cause of most childhood leukaemia.

The recommendations now being considered by the International Commission on Radiological Protection include occupational dose limits of $100 \mathrm{mSv}$ in 5 years and $50 \mathrm{mSv}$ in any year. These will ensure that almost no workers will exceed $10 \mathrm{mSv}$ in the 6 months before conception or 200 $\mathrm{mSv}$ in total before conception. For continued occupational exposure at these limits, the commission estimates the risk of serious hereditary effects to be about $6 \times 10^{-3}$, or about $2.5 \times 10^{-3}$ per child born to a highly exposed worker. The commission will need to consider whether this estimate needs to be revised in the light of the new data.

Several reservations must be recorded. The relative risk estimates have wide confidence limits. They depend on a total of 5 cases and 11 controls. Second, the relative risk has been assessed only up to and including the age of 24. This is appropriate for leukaemia, but leaves open the possibility of a less easily observed excess risk of other cancers with longer latency periods. Third, the association of relative risk and paternal employment is also seen in workers in the iron and steel industry. A reduced relative risk is seen in coal mining. There may be causal factors other than external radiation.

\section{Thames Street,}

St Ebbes, Oxford OX1 1SU, UK

1. Gardner, M.J. et al. Br. med. J. 300, 423-429 (1990) 2. OPCS 1988 Mortality Statistics, Series DH2 No. 13 (HMSO, 1988).

\section{Current opinion}

SIR-In their retrospective article', Bynum and Heilbron's references to the electric chair are not entirely correct.

First, the company of Westinghouse took absolutely no part in the construction or installation of the electric chairs at prisons in New York State; in fact, Westinghouse did everything humanly and legally possible to block execution by alternating current ${ }^{2.3}$, including seeking to abolish capital punishment in the state ${ }^{2}$. The work was in the hands of an Edison associate, Harold P. Brown ${ }^{4}$, who secretly arranged the purchase of secondhand Westinghouse a.c. generators from Oneonta $^{5}$ via intermediaries in Rio de Janeiro ${ }^{6}$. As soon as Westinghouse discovered what had happened, steps were taken to recover the generators on the grounds that they had been obtained by fraud, but the action was later dropped ${ }^{6}$.

Second, William Kemmler was electrocuted twice ${ }^{7}$ at Auburn prison, not three times, as reported by La Nature ${ }^{\prime}$. Shortly after the first exposure to 1,400 volts for 17 seconds, Kemmler began to recover. It took a little while before the second shock, lasting over 2 minutes, was applied'. Edison blamed the doctors present for the fiasco; Westinghouse also attended, and commented that the doctors could have done better with an axe ${ }^{6}$.

The electric chair played a major role in the vicious campaign of dirty tricks waged by the Edison camp, which was anxious to promote d.c. ${ }^{1.6}$, against Westinghouse and his gifted associate Tesla, who were exploiting the impressive technical advantages of a.c. Edison's purpose was to stigmatize a.c. by convincing and widely publicized demonstrations of its ability to kill $^{4.8}$. The medical ${ }^{8.9}$ and trade ${ }^{10}$ press were heavily on the side of Edison, who took detailed steps to convince the authorities of the soundness of his case $e^{11,-14}$. That almost a century later the facts of the case should still be misunderstood is no mean testimony to Edison's talent for misrepresentation.

30 Poplar Walk,

ROBERT JONES

London SE24, UK

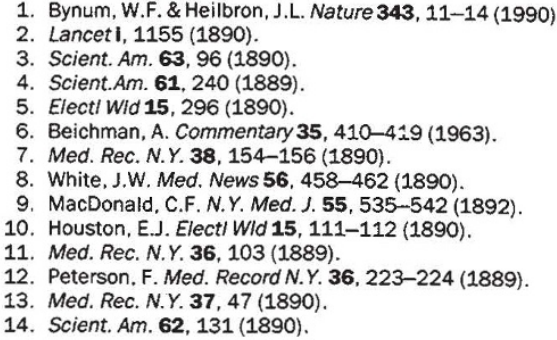

\section{Sexual attitudes}

SIR-The pilot survey for the British National Survey of Sexual Attitudes and Lifestyles quoted male respondents as reporting 2.9 times as many sexual partners as women. S. J. Gurman commented (Nature 342, 12; 1989) that this cannot be correct, but it is not so surprising that men have more heterosexual partners than women.

On the basis of the number of prostitutes in Switzerland ${ }^{1}$ as a proportion of the total female population one can estimate that there are 30,946 prostitutes in Britain. In Switzerland, each has an average of one new partner every two days, so that, in Britain in one year (300 working days), there will be about $4,641,900$ different sexual partnerships, equivalent to $232,095,000$ partnerships during 50 years of sexually active life. This estimate implies that every British male has a lifelong average of 9 different sexual partners on the basis of prostitution alone.

If, in the survey, the number of prostitutes in the sample of women is underrepresented or if the median value of partnerships rather than the average were considered, the results that give more heterosexual partners for men than for women are not so surprising, although Mrs Thatcher may doubt its value.

GIANFRANCO DOMENIGHETTI Claude France Carrel

Department of Social Affairs,

Cantonal Health Office,

Bellinzona, Switzerland

1. Uebersicht über die Prostitution in der Schweiz (Bundesant für Gesundheitswesen, Bern, 1989).

\section{Gone away . . .}

SIR - With reference to J. F. Lamb's letter (Nature 343, 404; 1990), I would suggest that British science is as alive and well as it has ever been. Its just that it is currently living in the United States.

Department of Clinical Oncology,

Royal Hallamshire Hospital, Sheffield S10 2JF, UK 